$1-1-2013$

\title{
Spectroscopic Analysis of Polymerization and Exonuclease Proofreading By A High-Fidelity DNA Polymerase During Translesion DNA Synthesis
}

\author{
Babho Devadoss \\ Case Western Reserve University \\ Irene Lee \\ Case Western Reserve University \\ Anthony J. Berdis \\ Cleveland State University, A.BERDIS@csuohio.edu
}

Follow this and additional works at: https://engagedscholarship.csuohio.edu/scichem_facpub

Part of the Biochemistry Commons, and the Chemistry Commons

How does access to this work benefit you? Let us know!

\section{Recommended Citation}

Devadoss, Babho; Lee, Irene; and Berdis, Anthony J., "Spectroscopic Analysis of Polymerization and Exonuclease Proofreading By A High-Fidelity DNA Polymerase During Translesion DNA Synthesis" (2013). Chemistry Faculty Publications. 215.

https://engagedscholarship.csuohio.edu/scichem_facpub/215

This Article is brought to you for free and open access by the Chemistry Department at EngagedScholarship@CSU. It has been accepted for inclusion in Chemistry Faculty Publications by an authorized administrator of EngagedScholarship@CSU. For more information, please contact library.es@csuohio.edu. 


\title{
Spectroscopic analysis of polymerization and exonuclease proofreading by a high-fidelity DNA polymerase during translesion DNA synthesis
}

\author{
Babho Devadoss , Irene Lee , Anthony J. Berdis
}

\section{Introduction}

DNA polymerases play essential roles in accurately replicating geno mic material. One of the most faithful DNA polymerases studied to date is the bacteriophage T4 DNA polymerase (gp43) [1]. When replicating undamaged DNA, gp43 displays remarkably high fidelity by allowing only one dNMP misincorporation event per $10^{8}$ turnovers [2]. Base substitution frequencies for other DNA polymerases range significantly. For example, replicative DNA polymerases such as mammalian DNA po lymerase delta and the Escherichia coli DNA polymerase III holoenzyme

Abbreviations: gp43, wild-type bacteriophage T4 DNA polymerase; gp43exo , exonuclease-deficient bacteriophage T4 DNA polymerase; dATP, deoxyadenosine triphosphate; dGTP, deoxyguanosine triphosphate; 2-APTP, 2-aminopurine-2'-deoxyribose triphosphate; 5-NapITP, 5-naphthyl-indole-2'-deoxyribose triphosphate; EDTA, ethylenediaminetetraacetate sodium salt; DTT, dithiothreitol; dNTP, deoxynucleoside triphosphate; Pol, DNA polvmerase show low base substitution frequencies of one misincorporation event per $10^{6}$ and $\sim 10^{7}$ turnovers, respectively [3,4]. However, other polymer ases such as HIV 1 reverse transcriptase [5] and mouse myeloma DNA polymerase beta [6] are far less faithful when replicating DNA displaying higher mutational frequencies of $\sim 1$ error every 5000 poly merization events.

Gp43, like most replicative polymerases, utilizes the multiplicative process outlined in Fig. 1A to maintain genomic fidelity [7]. This kinetic scheme encompasses three major control points for achieving fidelity: nucleobase selection and insertion ( step A), removal of a misinserted nucleotide via exonuclease processing ( $\operatorname{step} B$ ), and enzyme dissociation from primer/templates that are misaligned due to mispairing (step $C$ ). In the case of gp43, the most important step for maintaining fidelity is the DNA polymerization step which encompasses several microscopic kinetic events including binding of dNTP to the Pol:DNA complex, a con formational change in the Pol:DNA complex, and phosphoryl transfer (Fig. 1B). Discrimination against misinsertion is proposed to be achieved through a combination of improper binding (step 2), inappropriate orientation (step 3), and/or diminished rate of phosphoryl transfer (step 4). These microscopic events collectively function to provide an error frequency of 1 misincorporation event per $10^{5} 10^{6}$ turnovers [8]. 
A

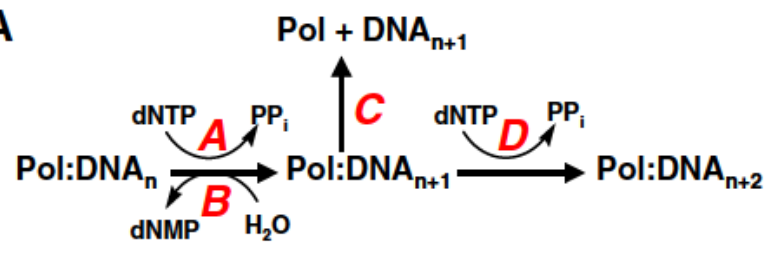

B

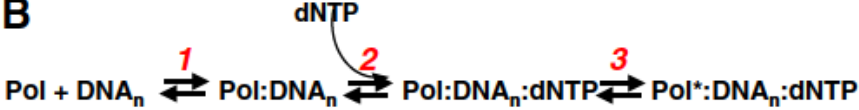

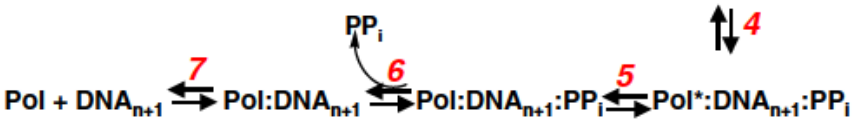

Fig. 1. (A) Mechanisms used to maintain genomic fidelity during DNA replication. Step A indicates nucleotide selection and insertion, step B indicates removal of misinserted nucleotides by exonuclease activity, step $C$ reflects enzyme dissociation from DNA, and step D reflects elongation beyond the formed mismatch. (B) Minimal kinetic mechanism for nucleotide incorporation catalyzed by gp 43, the high-fidelity bacteriophage T4 DNA polymerase. Step 1 represents binding of polymerase to DNA substrate. Step 2 represents dNTP binding to the polymerase:nucleic acid complex. Step 3 represents the conformational change preceding phosphoryl transfer. Step 4 represents the phosphoryl transfer step. Step 5 represents the conformational change after phosphoryl transfer. Step 6 represents release of pyrophosphate as the first product. Step 7 represents release of polymerase from extended nucleic acid product.

Despite these kinetic barriers, genomic mistakes can occur if a nu cleotide is misincorporated opposite a non complementary partner. In these instances, the proofreading capability of the associated exo nuclease domain reduces the error frequency by an additional 1000 fold [9]. While the activities of polymerization and exonuclease activities have been extensively studied during the replication of normal DNA [10 14], there is relatively little known on how these activities are coordinated during translesion DNA synthesis. The misreplication of damaged DNA is an important biomedical concern as translesion DNA synthesis can increase the probability of generat ing mutations. Indeed, defects in polymerase and exonuclease activi ties are associated with various genetic diseases including cancer [15 17]. As such, elucidating the biochemical mechanisms regulating polymerization and exonuclease activities is an important challenge in understanding how genomic fidelity is maintained and how de fects in these activities give rise to various pathological conditions.

Accurately studying the concerted efforts of polymerase and exo nuclease activities has been hindered due to the lack of chemical en tities that can accurately probe these reactions. For example, most natural nucleotides display poor kinetic behavior when incorporated opposite miscoding and non coding DNA lesions. In general, the cat alytic efficiencies for incorporating natural nucleotides opposite most DNA lesions are $>1000$ fold lower than those measured during the replication of undamaged DNA [18 21]. In addition, natural nu cleotides are spectroscopically inactive. There are, however, several examples of fluorescent analogs that can be used as surrogates for natural dNTPs [22 28 ]. In particular, Tor and co workers have devel oped pyrrolo dC as a fluorescent pyrimidine analog [22] whereas Saito and colleagues have developed fluorescent triazole deoxycytidine analogs $[23,24]$. In addition, several pteridine analogs of guanine and ad enine have been reported $[25,26]$. Finally, Wilhelmsom and co workers recently described a novel fluorescent triazole adenine analog that was developed using "click" chemistry [27]. However, perhaps the most widely used analog for enzymological studies of DNA synthesis is 2 aminopurine deoxyribose triphosphate (2 APTP), a highly fluorescent analog of dATP [28 30]. Most biochemical studies using this nucleotide analog place the fluorogenic analog into single stranded DNA $[28,29]$ or double stranded DNA [31] as a way to measure conformational changes in nucleic acid. Since 2 APTP has a significantly higher intrinsic fluores cence while free in solution, experiments designed to directly measure its incorporation into DNA are technically challenging as the concentra tion of 2 APTP must be maintained low $(<5 \mu \mathrm{M})$. This low concentration is typically below the $K_{m}$ value for insertion of the nucleotide opposite damaged DNA, and this kinetic feature hinders its use to monitor the kinetics of nucleotide incorporation and excision, particularly during translesion DNA synthesis.

These deficiencies mandate that discontinuous assays be used to study nucleotide incorporation and excision independently. This creates a serious complication as the inability to study both reactions simulta neously provides indirect evidence for kinetic events associated with the interaction between each active site. To circumvent these complica tions, this report describes the use of a non natural nucleotide designat ed 5 naphthyl indole 2' deoxyribose triphosphate (5 NapITP) (Fig. 2A) as a spectroscopic probe to study both polymerization and exonuclease proofreading activities during translesion DNA synthesis. Since this non natural nucleotide is highly conjugated, it is highly fluorescent while free in solution and this fluorescence becomes quenched upon in corporation into DNA [31]. In addition, the binding affinity of 5 NapITP during the replication of various DNA lesions including abasic sites and cyclobutane thymine dimers is relatively high $\left(\mathrm{K}_{\mathrm{d}} \sim 10 \mu \mathrm{M}\right)$ [32]. These features collectively suggest that 5 NapITP could function as a common and spectroscopically active analog to study the coordination of nucleo tide incorporation and excision during translesion DNA synthesis. The analyses provided here demonstrate the existence of distinct nuances in the mechanism by which structurally diverse DNA lesions are repli cated. In addition, our studies reveal the presence of a fluorescence recovery phase that corresponds to the formation of a pre excision com plex that precedes hydrolytic excision of the non natural nucleotide. The rate constant for forming this complex is lesion dependent, indicating that exonuclease proofreading is regulated by the physical composition and nature of the DNA lesion. Taken together, this work provides the first demonstration of a unique non natural nucleotide that can be used for real time spectroscopic analyses to probe the coordinated ef forts of polymerization and exonuclease proofreading.

\section{Methods and materials}

\section{Materials}

$\left[\gamma-{ }^{32} \mathrm{P}\right]$ ATP was purchased from MP Biomedical (Irvine, CA). Unlabelled dNTPs (ultrapure) were obtained from Pharmacia. $\mathrm{MgCl}_{2}$ and Trizma base were from Sigma. Urea, acrylamide, and bis acrylamide were from Aldrich. Oligonucleotides, including those containing a tetra hydrofuran moiety mimicking an abasic site, were synthesized by Operon Technologies (Alameda, CA). Oligonucleotides containing thymine di mers were synthesized by TriLink Biotechnologies (San Diego, CA). 5 NapITP was synthesized and purified as previously reported [31]. All other materials were obtained from commercial sources and were of the highest available quality. Wild type gp43 and

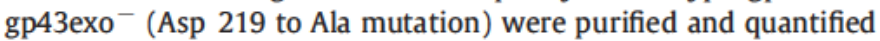
as previously described [33]. 14Nap mer was generated by reacting single stranded 13 mer DNA $(10 \mathrm{mM})$ with $20 \mu \mathrm{M} 5$ NapITP with 0.2 units terminal deoxynucleotidyl transferase (Fisher) for $30 \mathrm{~min}$ at $37^{\circ} \mathrm{C}$. The reaction was heated at $65{ }^{\circ} \mathrm{C}$ for $10 \mathrm{~min}$ to thermally denature the polymerase. DNA was separated from unreacted 5 NapITP using G25 spin columns as described [34]. An aliquot of the DNA was treated with $\left[\gamma-{ }^{32} \mathrm{P}\right]$ ATP and 0.1 unit polynucleotide kinase for $30 \mathrm{~min}$ at $37^{\circ} \mathrm{C}$, and the reaction was analyzed by denaturing gel electrophoresis to vali date incorporation of 5 NapIMP to form the corresponding 14 mer.

\section{Enzyme assays}

The assay buffer used in all kinetic studies consisted of TrisOAc (25 mM pH 7.5), KOAc (150 mM), and DTT (10 mM) at pH 7.5. All 


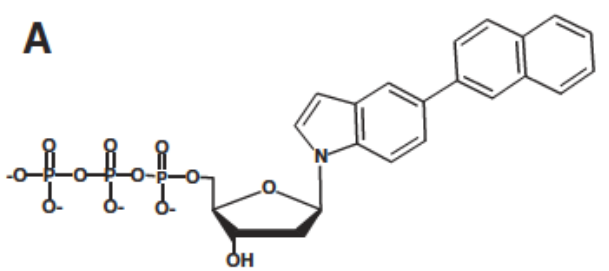

5-NapITP

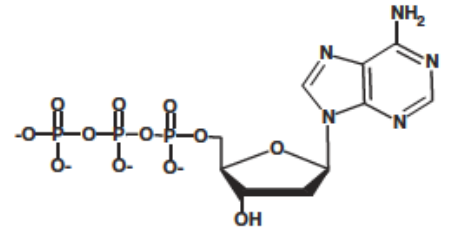

dATP

B

$5^{\prime}$ - TCGCAGCCGGTCC

3' -AGCGTCGGCCAGGXCCAAA<smiles>CCCCCCn1cc(C)c(=O)[nH]c1=O</smiles>

Thymine (T)

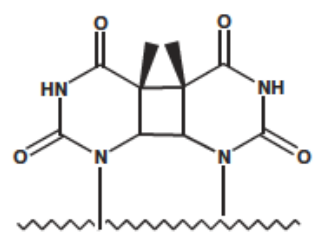

Thymine Dimer $(\mathrm{T}=\mathrm{T})$

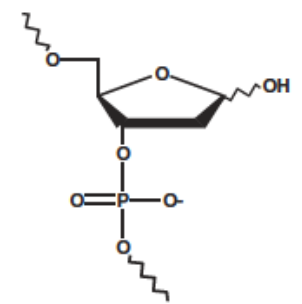

Abasic Site (Sp)

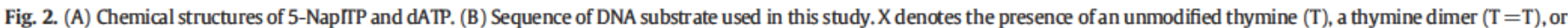
an abasic site (Sp). The chemical structures of normal nucleobase and DNA lesions are also provided to highlight structural diversity between normal and damaged DNA.

assays were performed at $25^{\circ} \mathrm{C}$. Polymerization reactions were moni tored by analysis of the products of $20 \%$ sequencing gels as previously de scribed. Gel images were obtained with a Packard PhosphorImager by using the OptiQuant software supplied by the manufacturer. Product for mation was quantified by measuring the ratio of ${ }^{32} \mathrm{P}$ labeled extended and un extended primer. The ratios of product formation are corrected for substrate in the absence of polymerase (zero point). Corrected ratios are then multiplied by the concentration of primer/template used in each assay to yield total product.

\section{Pre steady state nucleotide incorporation assays}

A rapid quench instrument (KinTeK Corporation, Clarence, PA) was used to measure time courses in the incorporation of 5 NapITP with all DNA substrates. Experiments were performed under single turnover reaction conditions such that the concentrations of poly merase and nucleotide substrates were maintained in molar excess versus that of DNA substrate. A typical reaction was performed by rapidly mixing an aliquot of a preincubated solution of DNA polymer ase $(1 \mu \mathrm{M})$ and 5 NapITP $(4 \mu \mathrm{M})$ in assay buffer containing EDTA $(100 \mu \mathrm{M})$ with an equal volume of solution containing DNA $(500 \mathrm{nM})$ and $\mathrm{Mg}(\mathrm{OAc})_{2}(10 \mathrm{mM})$. After mixing the solutions in the rapid quench flow instrument for time intervals ranging from 0.1 to $60 \mathrm{~s}$, the reactions were quenched by the addition of EDTA $(350 \mathrm{mM})$ through the third syringe of the instrument. Reaction products were then analyzed as described above. Data obtained for single turnover DNA polymerization assays were fitted to Eq. (1):

y $\quad A^{*}\left(1-e^{k t}\right)+C$

where $\mathrm{A}$ is the burst amplitude, $\mathrm{k}$ is the observed rate constant in product formation, $t$ is time, and $C$ is the end point of the reaction.

In some cases, polymerization reactions performed under single turnover conditions were quenched by the addition of $1 \mathrm{M} \mathrm{HCl}$ to denature the protein catalyst. Acid quenched samples were extracted using $100 \mu \mathrm{L}$ of phenol/chloroform/isoamyl alcohol and then neutral ized by the addition of approximately $25 \mu \mathrm{L} 3 \mathrm{M} \mathrm{NaOH} / 1 \mathrm{M}$ Tris. Reaction products were analyzed as described above and fitted to Eq. (1).

Polymerization reactions were also performed using pseudo first order reaction conditions in which the concentrations of DNA sub strate and 5 NapITP were maintained in molar excess versus the con centration of DNA polymerase. A typical reaction was performed by rapidly mixing an aliquot of a preincubated solution of DNA polymerase $(100 \mathrm{nM})$ and 5 NapITP $(4 \mu \mathrm{M})$ in assay buffer containing EDTA $(100 \mu \mathrm{M})$ with an equal volume of solution containing DNA $(500 \mathrm{nM})$ and $\mathrm{Mg}(\mathrm{OAc})_{2}(10 \mathrm{mM})$. Reaction products were performed using the rapid quench instrument and then analyzed as described above. Data obtained for polymerization assays performed under pseudo first order conditions were fitted to Eq. (2):

y $\quad A^{*}\left(1-e^{k t}\right)+B t+C$

where $\mathrm{A}$ is the burst amplitude, $\mathrm{k}$ is the observed rate constant in prod uct formation, tis time, $\mathrm{B}$ is the slope of the second slower phase, and $\mathrm{C}$ is the end point of the reaction.

\section{Stopped flow fluorescence analyses}

5 NapITP is a highly conjugated, $\pi$ electron rich nucleotide that can be excited at $255 \mathrm{~nm}$ and the changes in the fluorescence can be measured at $349 \mathrm{~nm}$ without interference from tryptophan fluo rescence. Emission spectra for monitoring the insertion of 5 NapITP opposite an abasic site, thymine dimer and thymine were obtained by using a stopped flow instrument (KinTek Corporation (Clarence, PA)). Samples were excited at $255 \mathrm{~nm}$, and fluorescence emission data were collected by using a cut off filter that measures emission wavelength greater than $340 \mathrm{~nm}$. Assays were performed under 
single turnover conditions as described above for pre steady state polymerization reactions. A typical reaction was performed by rapidly mixing an aliquot of a preincubated solution of DNA polymerase $(1 \mu \mathrm{M})$ and DNA $(500 \mathrm{nM})$ in assay buffer containing EDTA $(100 \mu \mathrm{M})$ with an equal volume of solution containing nucleotide analog $(4 \mu \mathrm{M})$ and $\mathrm{Mg}(\mathrm{OAc})_{2}(10 \mathrm{mM})$. Data obtained for single turnover DNA poly merization assays were fitted to Eq. (3):

y $\quad \mathrm{Ae}^{\mathrm{kt}}+\mathrm{C}$

where $\mathrm{A}$ is the burst amplitude, $\mathrm{k}$ is the observed rate constant in fluo rescence quenching, $\mathrm{t}$ is time, and $\mathrm{C}$ is the end point of the reaction.

\subsection{Quantifying the inhibitory effects of dATP on the incorporation of 5 NapITP}

The ability of dATP to inhibit 5 NapIMP incorporation opposite an abasic site or thymine dimer was measured using the fluorescence of the non natural nucleotide. A typical reaction was performed by rap idly mixing an aliquot of a preincubated solution of DNA polymerase $(1 \mu \mathrm{M})$ and DNA (500 $\mathrm{nM})$ in assay buffer containing EDTA $(100 \mu \mathrm{M})$ with an equal volume of solution containing 5 NapITP $(4 \mu \mathrm{M})$, $\mathrm{Mg}(\mathrm{OAc})_{2}(10 \mathrm{mM})$, and variable concentrations of dATP $(0500 \mu \mathrm{M})$. Data obtained for these single turnover DNA polymerization reactions were fitted to Eq. (2). Apparent $K_{i}$ values, designated as $K_{i, a p p}$ values, were obtained using the $\mathrm{x}$ intercept from plots of 1 /amplitude versus dATP concentration. True inhibition constants, designated as $K_{i}$ values, were obtained using Eq. (4).

$\mathrm{K}_{\mathrm{i}} \quad \mathrm{K}_{\mathrm{i}, \mathrm{app}} /\left(1+\left([5-\mathrm{NapITP}] / \mathrm{K}_{\mathrm{m}}\right]\right)$

where $K_{i, a p p}$ is the apparent inhibition constant determined from the Dixon plot, [NapITP] is the concentration of non natural nucleotide substrate, and $\mathrm{K}_{\mathrm{m}}$ is the Michaelis constant for 5 NapITP. Measured $\mathrm{K}_{\mathrm{i}}$ values represent an average of two independent determinations.

\section{Idle turnover measurements}

Single turnover conditions were employed to measure the rates of excision of 5 NapIMP opposite an abasic site, thymine dimer, or thy mine. The reaction was initiated by mixing gp43 $(1 \mu \mathrm{M})$ with $250 \mathrm{nM}$ DNA and $4 \mu \mathrm{M} 5$ NapITP in assay buffer containing EDTA $(100 \mu \mathrm{M})$ and $30 \mu \mathrm{M}$ dATP and $10 \mathrm{mM} \mathrm{Mg}(\mathrm{OAc})_{2}$. Aliquots of the reactions were quenched with $350 \mathrm{mM}$ EDTA at variable times (5 $900 \mathrm{~s}$ ) and products were analyzed as described [34].

\section{Results}

\section{Incorporation of 5 NapITP opposite normal and damaged DNA}

Previous work demonstrated that the exonuclease deficient T4 DNA polymerase, gp43exo-, incorporates a wide variety of non natural nucleotides opposite an abasic site (Fig. 2B) [35 38]. 5 NapITP is a particular interesting analog as it is efficiently incorpo rated opposite this non instructional lesion with a low $\mathrm{K}_{\mathrm{d}}$ value of $10.3 \pm 4.5 \mu \mathrm{M}$ and a $\mathrm{k}_{\mathrm{pol}}$ of $27.1 \pm 1.5 \mathrm{~s}^{-1}$ [31]. Here, we compared the kinetics for the incorporation of 5 NapIMP opposite this non instructional lesion using a fluorescence quenching assay versus a conventional radiolabeled extension assay. Comparing the rate con stants obtained using each technique can identify the location of the rate limiting step along the reaction pathway. As previously described [39], the radiolabel assay measures product formation $\left(\mathrm{DNA}_{\mathrm{n}+1}\right)$ that occurs only after phosphoryl transfer (step 4) (Fig. 1B) whereas the fluo rescence assay can detect intermediates including ternary complexes such as Pol:DNA:dNTP (step 2) and Pol*:DNA:dNTP (step 3) that form prior to phosphoryl transfer (step 4). Thus, if phosphoryl transfer is completely rate limiting, the rate constant in fluorescence quenching (step 2 and/or step 3 ) should be faster than that of measuring product formation via the radiolabel assay. In contrast, identical rate constants would indicate that the conformational change preceding phosphoryl transfer is the rate limiting step. The data provided in Fig. 3A suggests that this latter mechanism is operative with the high fidelity T4 poly merase as the time course in fluorescence quenching of 5 NapITP oppo site an abasic site is essentially identical to its incorporation opposite the DNA lesion. Fits of each time course to a single exponential process val idate that the rate constant of $5.4 \pm 0.1 \mathrm{~s}^{-1}$ in fluorescence quenching ( $\mathrm{k}_{\text {quench }}$ ) is identical to that of $5.5 \pm 0.1 \mathrm{~s}^{-1}$ for incorporating the non natural nucleotide $\left(\mathrm{k}_{\mathrm{inc}}\right)$. The $\mathrm{k}_{\mathrm{inc}}$ value of $5.5 \mathrm{~s}^{-1}$ measured here is significantly slower than the $k_{\text {pol }}$ value of $27.1 \mathrm{~s}^{-1}$ previ ously reported [31]. This low $\mathrm{k}_{\text {inc }}$ of $5.5 \mathrm{~s}^{-1}$ was measured using a concentration of $4 \mu \mathrm{M}$ of 5 NapITP that is 2.5 times below the $K_{d}$ value of $10.3 \mu \mathrm{M}$. In fact, application of the Michaelis Menten equation $\left(\mathrm{k}_{\mathrm{obs}}=\left(\mathrm{k}_{\mathrm{pol}} *[5 \mathrm{NapITP}]\right) /\left(\mathrm{K}_{\mathrm{d}}+[5 \mathrm{NapITP}]\right)\right)$ indicates that the measured $k_{\text {inc }}$ of $5.5 \mathrm{~s}^{-1}$ is nearly identical to the predicted rate con stant of $7.7 \mathrm{~s}^{-1}$.

The identity in the fluorescence quenching and nucleotide incorpo ration rate constants argues that the conformational change step pre ceding phosphoryl transfer is the rate limiting step for incorporating 5 NapIMP opposite an abasic site. To further validate this, we measured the incorporation of 5 NapIMP opposite this non instructional DNA le sion using pseudo first order reaction conditions in which the concen tration of DNA and 5 NapITP were maintained in molar excess versus DNA polymerase. The time course provided in Fig. 3B shows that prod uct formation is biphasic as there is a rapid initial "burst" in product for mation followed by a second, slower phase. This biphasic time course indicates that a kinetic step after phosphoryl transfer is rate limiting for enzyme turnover [40]. In addition, the initial burst in product forma tion is identical to the amount of polymerase used in the reaction. The stoichiometric burst in product formation argues that phosphoryl trans fer is not rate limiting for the insertion of 5 NapIMP opposite an abasic site. This was subsequently confirmed by comparing the kinetics of 5 NapIMP incorporation opposite an abasic site using $\mathrm{HCl}$ or EDTA as de naturing versus non denaturing quenching agents, respectively. As illus trated in Fig. 3C, the time courses in product formation are independent of quenching agent, and this result is consistent with a mechanism in which the conformational change step preceding phosphoryl transfer is the rate limiting step for 5 NapIMP incorporation opposite an abasic site [41]. Furthermore, the kinetic dissociation constant $\left(K_{d}\right)$ as well as the maximal rate constant for the fluorescence quenching $\left(\mathrm{k}_{\max }\right.$ quench $)$ of 5 NapITP opposite an abasic site was measured by varying the con centration of the non natural nucleotide from 1 to $16 \mu \mathrm{M}$ using single turnover reaction conditions. Fig. 3E shows the concentration depen dency of 5 NapITP on fluorescence quenching. Note that the amplitude in fluorescence quenching decreases as a function of increasing 5 NapITP concentrations, and the reduction prohibits accurately mea suring rate constants at 5 NapITP concentrations greater than $16 \mu \mathrm{M}$. Regardless, $\mathrm{k}_{\text {quench }}$ values at all concentrations of 5 NapITP tested here (1 $16 \mu \mathrm{M}$ ) were defined by fitting each time course to the equation for a single exponential decay (Eq. (3)). The plot of $\mathrm{k}_{\text {quench }}$ versus 5 NapITP concentration is hyperbolic (Fig. 3E) and a fit of the data to the Michaelis Menten equation provides a $\mathrm{K}_{\mathrm{D}}$ 5-PhITP of $9.2 \pm 1.4 \mu \mathrm{M}$ and a $\mathrm{k}_{\max }$ quench value of $38 \pm 10 \mathrm{~s}^{-1}$. The hyperbolic dependency of the rate constant on 5 NapITP concentration is indicative of a two step binding mechanism in which the conformational change preceding phosphoryl transfer is the rate limiting step for nucleotide incorporation opposite the abasic site. Finally, the identity in kinetic parameters mea sured using this fluorescence quenching assay versus a radiolabeled ex tension assay [31] is consistent with this mechanism.

We next evaluated if this mechanism is lesion dependent by mea suring the kinetics of 5 NapIMP incorporation opposite a thymine dimer, a miscoding DNA lesion that is structurally distinct from an abasic site (Fig. 2B). In this case, the $\mathrm{k}_{\text {quench }}$ of $1.03 \pm 0.05 \mathrm{~s}^{-1}$ is 
A

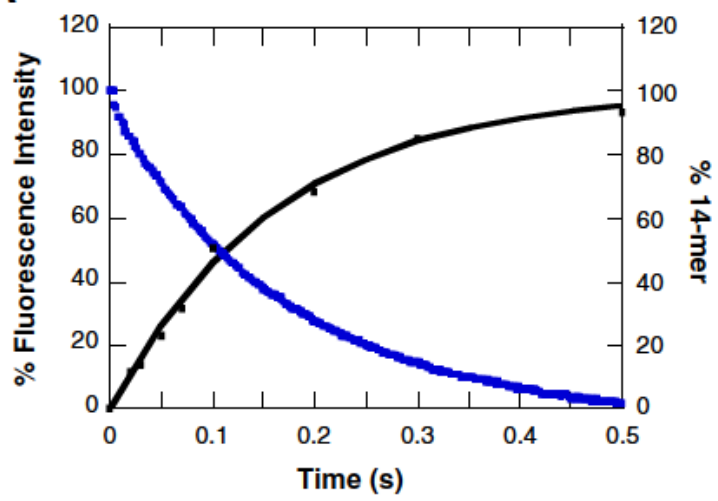

C

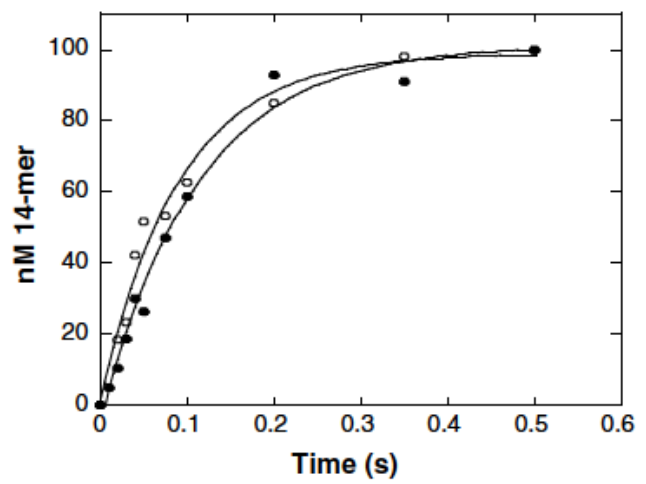

B

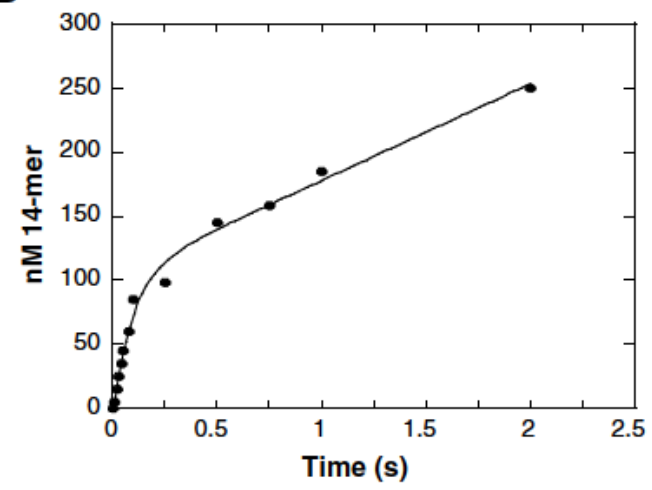

D

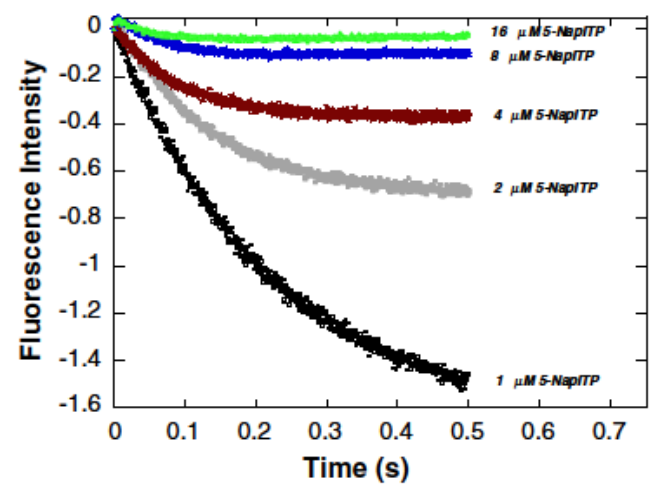

E

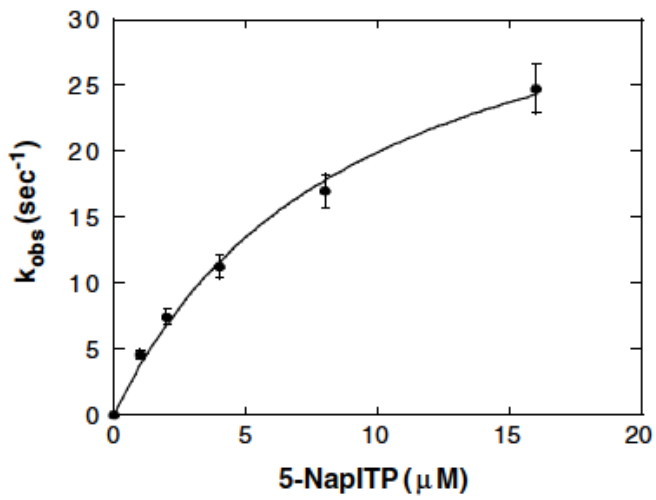

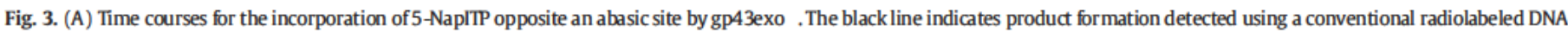

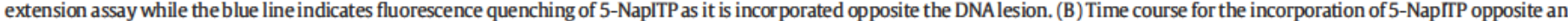

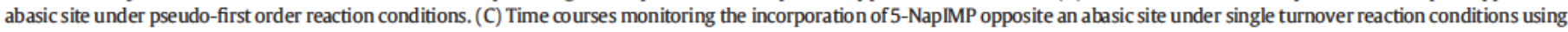

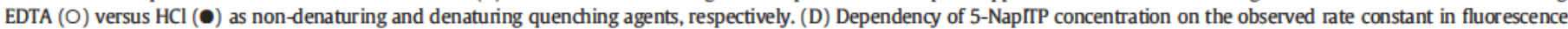

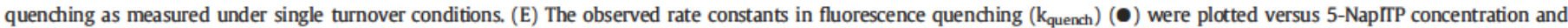
were fitted to the Michaelis-Menten equation to determine $K_{d}$ and $k_{\max }$ quench values.

$\sim 1.3$ fold faster than the $\mathrm{k}_{\text {inc }}$ of $0.77 \pm 0.02 \mathrm{~s}^{-1}$ measured using the radiolabeled extension assay (Fig. 4A). The faster rate constant in fluorescence quenching argues that base stacking of the non natural nucleotide opposite this bulky DNA lesion occurs prior to product for mation, i.e., phosphoryl transfer. To verify this conclusion, we applied the experimental paradigm described above to monitor the incorpo ration of 5 NapIMP opposite a thymine dimer using pseudo first order reaction conditions. The time course provided in Fig. 4B shows a rapid initial "burst" in product formation followed by a sec ond, slower phase. As before, the biphasic time course indicates that a kinetic step after phosphoryl transfer is rate limiting for enzyme turnover [40]. However, close inspection of the data shows that the initial burst in product formation of $70 \mathrm{nM}$ is lower than the amount polymerase used in the reaction $(100 \mathrm{nM})$. This sub stoichiometric burst in product formation is consistent with a mechanism in which phosphoryl transfer is partially rate limiting during the incorporation of 5 NapIMP opposite an abasic site. This mechanism was subsequently confirmed by comparing the kinetics of 5 NapIMP incorporation oppo site a thymine dimer using a denaturing $(\mathrm{HCl})$ or non denaturing quenching (EDTA) agent. As illustrated in Fig. 4C, the amplitude in prod uct formation using $\mathrm{HCl}$ is $\sim 30 \%$ lower than the amplitude in product formation using EDTA as the non denaturing quenching agent. This 
A

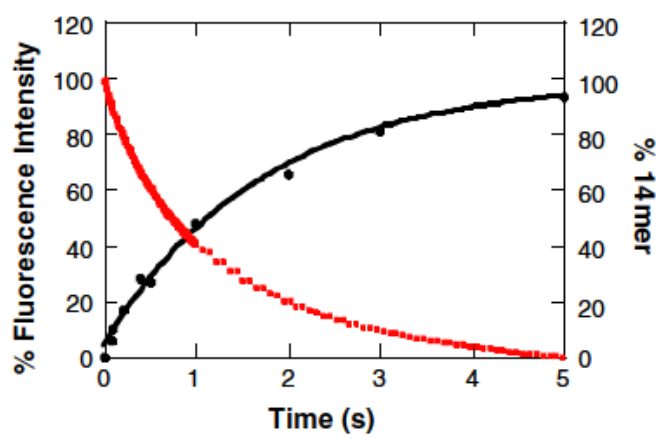

C

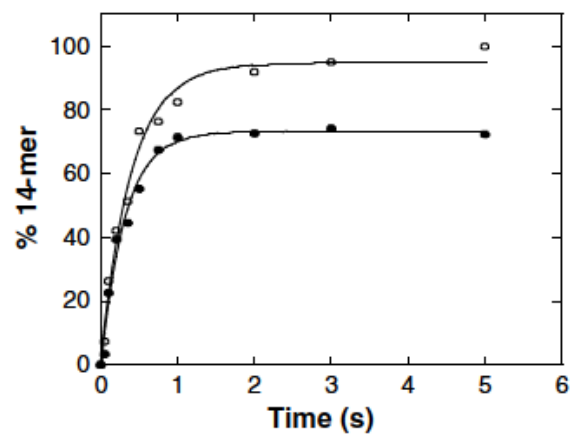

B

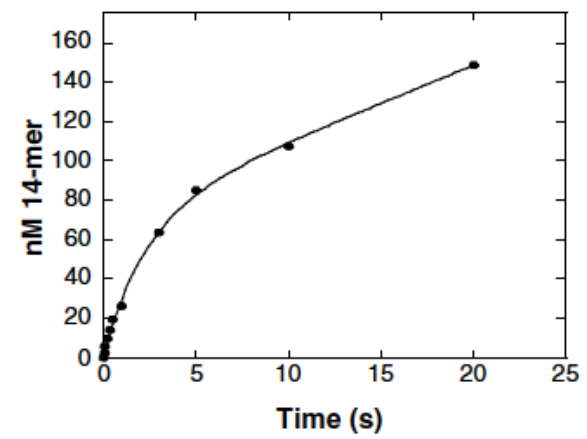

D

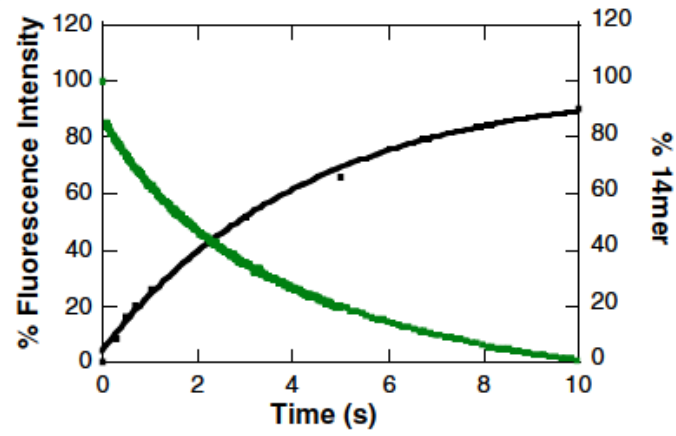

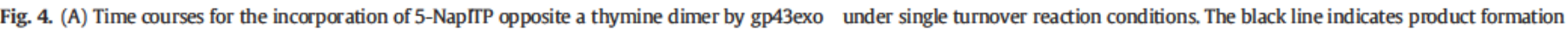

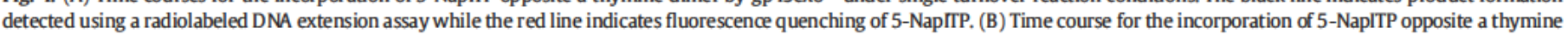

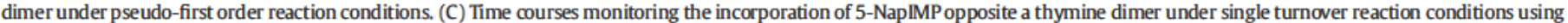

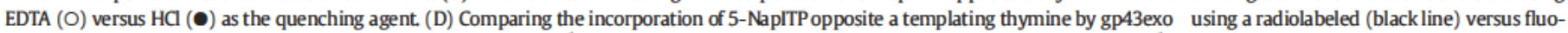
rescent quenching (green line) assay. The $\mathrm{k}_{\text {quench }}$ of $0.23 \pm 0.01 \mathrm{~s}{ }^{1}$ opposite thymine is essentially identical to the $\mathrm{k}_{\text {inc }}$ of $0.22 \pm 0.01 \mathrm{~s}{ }^{1}$ measured using the radiolabeled assay.

difference in amplitude as a function of quenching agent argues that phosphoryl transfer is a partially rate limiting step for 5 NapIMP incor poration opposite a thymine dimer. Collectively, these data suggest that the phosphoryl transfer step is at least partially rate limiting for incor porating 5 NapIMP opposite the bulky DNA lesion and argues that the mechanism for replicating a miscoding thymine dimer is different than replicating the non instructional abasic site.

Identical experiments were performed monitoring the incorporation of 5 NapITP opposite a templating thymine to compare normal versus translesion DNA synthesis. The $\mathrm{k}_{\text {quench }}$ of $0.23 \pm 0.01 \mathrm{~s}^{-1}$ opposite thy mine is essentially identical to the $\mathrm{k}_{\text {inc }}$ of $0.22 \pm 0.01 \mathrm{~s}^{-1}$ measured using the radiolabeled assay (Fig. 4D). Similar analyses measuring the 5 NapIMP incorporation opposite cytosine yield a $\mathrm{k}_{\text {quench }}$ of $0.25 \pm$ $0.01 \mathrm{~s}^{-1}$ and $\mathrm{k}_{\text {inc }}$ of $0.20 \pm 0.01 \mathrm{~s}^{-1}$ (data not shown). In both cases, the identity in rate constants indicates that phosphoryl transfer does not limit the rate for incorporating 5 NapIMP opposite undamaged DNA. A summary of rate constants for fluorescence quenching and in corporation of 5 NapIMP as a function of DNA template is provided in Table 1.

Competition experiments to measure the binding affinities of natural nucleotides

The fluorescent quenching capabilities of 5 NapITP was also used as a spectroscopic tool to directly measure the binding affinities of natural dNTPs with different DNA lesions. In these experiments, a pre incubated solution of $1 \mu \mathrm{M}$ gp $43 \mathrm{exo}^{-}$and $500 \mathrm{nM}$ 13/20Sp mer was mixed with $4 \mu \mathrm{M} 5 \mathrm{NapITP}$ and variable concentrations of dATP $(0100 \mu \mathrm{M})$. As illustrated in Fig. 5A, the addition of increasing con centrations of dATP reduces the amplitude phase of fluorescence quenching. This decrease occurs since the binding of dATP opposite the abasic site prevents 5 NapITP binding and results in a decreased amplitude in fluorescence quenching. Since the rate constant for incorpo rating dAMP opposite an abasic site is relatively slow $\left(\mathrm{k}_{\mathrm{pol}}=0.15 \mathrm{~s}^{-1}\right)$ [42], the reduction in fluorescence signal under the time frame tested $(<1 \mathrm{~s})$ is caused by competitive binding between dATP and 5 NapITP rather than through dATP incorporation. Dixon plot analysis (plot of 1 /amplitude versus dATP concentration) pro vides a $K_{i, a p p}$ of $90 \pm 5 \mu \mathrm{M}$ for dATP (Fig. 5B). Correcting for the concentration of 5 NapITP via the application of the Cheng Prusoff equation [43] yields a true $K_{i}$ value of $64 \pm 3 \mu \mathrm{M}$ for dATP. This value is essentially identical to the reported $K_{m}$ value of $80 \pm$ $10 \mu \mathrm{M}$ for dATP [42].

Similar analyses were performed measuring the ability of dATP to in hibit the incorporation of 5 NapIMP opposite a thymine dimer. Previous kinetic analyses with the high fidelity T4 DNA polymerase could not ac curately define a $\mathrm{K}_{\mathrm{d}}$ value since the rate constant for incorporating dAMP is extremely slow ( $\mathrm{k}_{\mathrm{obs}}=0.007 \mathrm{~s}^{-1}$ ) even at a high concentration of $500 \mu \mathrm{M}[41]$. As expected, increasing the concentrations of dATP causes a reduction in the amplitude phase of 5 NapITP fluorescence quenching for incorporation opposite the thymine dimer (Fig. 5C). Dixon plot

Table 1

Summary of kinetic rate constants of 5-NapITP incorporation opposite DNA lesions and undamaged DNA by the exonuclease-deficient bacteriophage T4 DNA polymerase.

\begin{tabular}{lcc}
\hline DNA & $k_{\text {inc }}\left(\mathrm{s}^{1}\right)^{\mathrm{a}}$ & $\mathbf{k}_{\text {quench }}\left(\mathrm{s}^{1}\right)^{\mathrm{b}}$ \\
\hline $13 / 20_{\mathrm{SP}}$ & $5.5 \pm 0.1$ & $5.4 \pm 0.1$ \\
$13 / 20_{\mathrm{T}} \mathrm{T}_{13 / 20_{\mathrm{T}}}$ & $0.77 \pm 0.02$ & $1.03 \pm 0.05$ \\
$13 / 20_{\mathrm{C}}$ & $0.22 \pm 0.01$ & $0.23 \pm 0.01$ \\
\hline
\end{tabular}

${ }^{a} k_{\text {inc }}$ values are observed rate constants for the enzymatic incorporation of 5-NapITP opposite undamaged or damaged DNA.

${ }^{b} \mathrm{k}_{\text {quench }}$ values are observed rate constants for the quenching in fluorescence of 5-NapITP. 
A

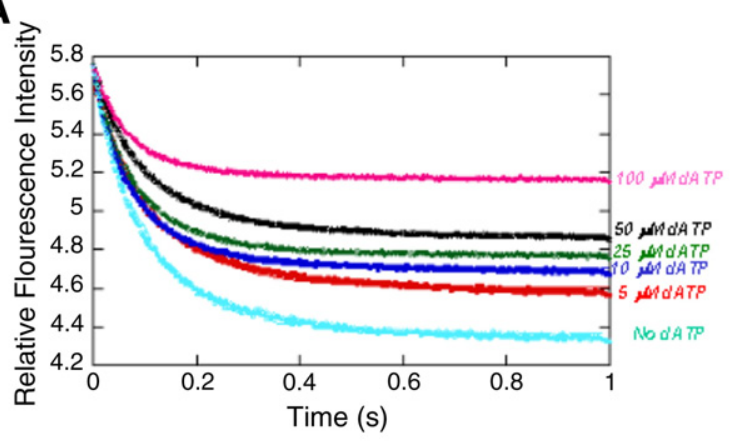

C

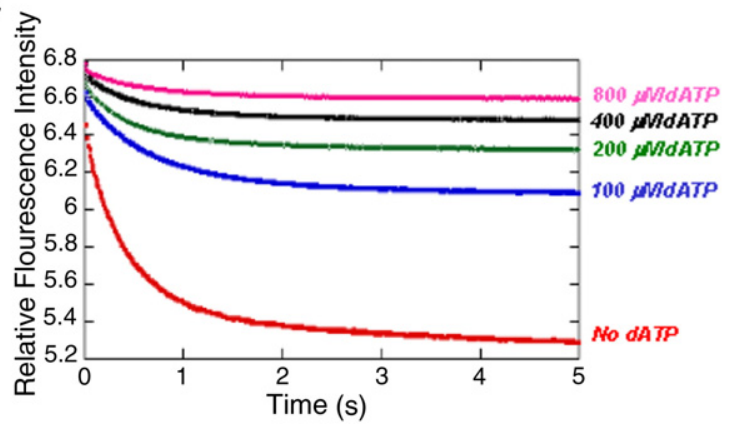

B

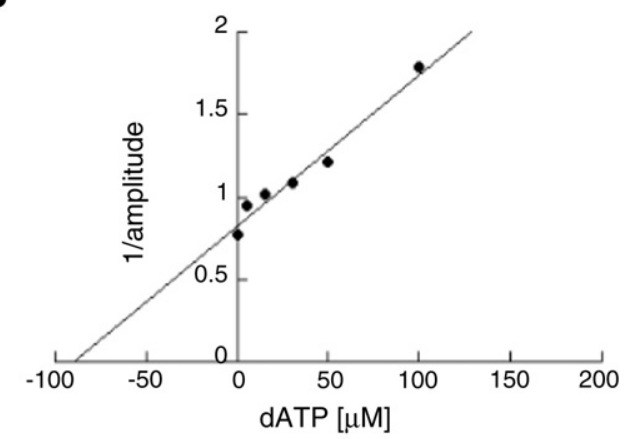

D

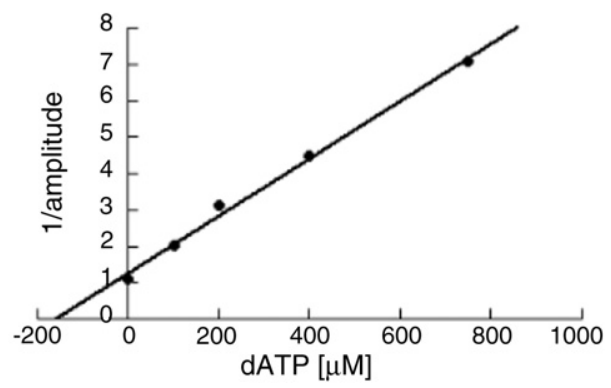

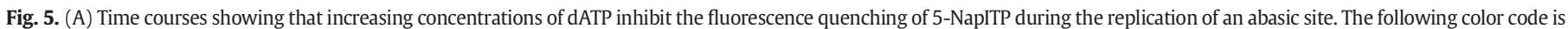

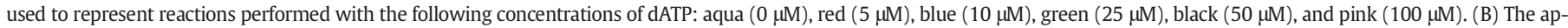

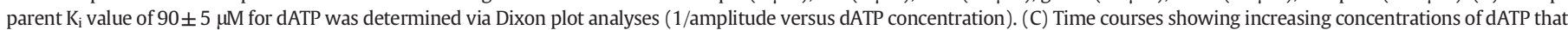

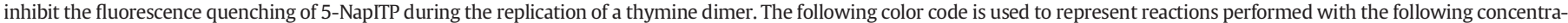

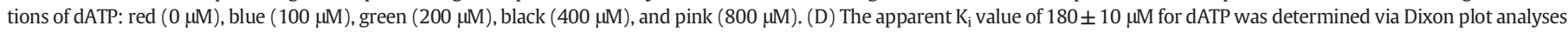
(1/amplitude versus dATP concentration).

analysis (Fig. 5D) followed by correction for the concentration of 5 NapITP using the Cheng Prusoff equation [43] yields a true $K_{i}$ value of $125 \pm 20 \mu \mathrm{M}$ for dATP opposite the thymine dimer.

\section{Exonuclease proofreading is lesion dependent}

Exonuclease proofreading plays an important role in maintaining ge nomic fidelity by removing misincorporated nucleotides. This activity was evaluated during normal and translesion DNA synthesis by moni toring the stable incorporation of 5 NapIMP opposite undamaged and damaged DNA by wild type DNA polymerase. Fig. 6A compares time courses in the fluorescence change of 5 NapITP with gp43 (blue line) and gp43exo- (red line) during the replication of an abasic site. Both polymerases display a rapid decrease in fluorescence that is associated with base stacking of 5 NapITP caused by the incorporation of the non natural nucleotide opposite the lesion. The $\mathrm{k}_{\text {quench }}$ values are independent of exonuclease proofreading as both wild type and exonuclease deficient polymerases yield identical rate constants of $5.6 \pm 0.1 \mathrm{~s}^{-1}$. However, the time course with gp43 is distinct due to the presence of a second, slower phase of fluorescence recovery. It is unlikely that this recovery in fluorescence is caused by polymerase dissociation since a similar phenomenon is not observed using the exonuclease deficient DNA polymerase under identical conditions. As such, this fluorescence recovery phase could reflect two distinct kinetic steps: 1.) exonucleolytic removal of 5 NapIMP from DNA or 2.) "unstacking" of the non natural nucleotide via partitioning between po lymerase and exonuclease active sites.

To distinguish between these possibilities, idle turnover experiments were performed using a modified gel electrophoresis protocol [34] to measure the kinetics of incorporation and excision of the non natural nucleotide. The process of idle turnover occurs when a DNA polymerase incorporates a dNTP and then excises it in the absence of the next required nucleotide triphosphate. This activity likely occurs under in vivo conditions since the polymerase should be bound and stalled at the DNA lesion. Idle turnover was quantified using a modified gel elec trophoresis protocol that monitors the amount of extension and subse quent excision of the primer as a function of time. Since experiments are performed using single turnover reaction conditions, the rate constants in product formation reflect the kinetics of insertion and excision rather than polymerase dissociation from the mispair. Fig. 6B shows that the time course for incorporating and excising 5 NapIMP opposite an abasic site (blue line) differs significantly from the corresponding time course measuring fluorescence quenching and recovery (black line). Kinetic simulation of the time courses in nucleotide incorporation and excision using the radiolabeled assay was performed as previously described [34] to calculate the $k_{\text {exo }}$ value. In the case of an abasic site, the $k_{\text {exo }}$ value of $0.024 \pm 0.004 \mathrm{~s}^{-1}$ is $\sim 7$ fold slower than the $k_{\text {recovery }}$ of $0.17 \pm 0.01 \mathrm{~s}^{-1}$ measured from the fluorogenic assay. The difference in rate constants is consistent with a mechanism in which the incorporated 5 NapITP be comes "un stacked" via the formation of a pre exonuclease complex, and that formation of this complex precedes enzymatic hydrolysis in the exonuclease active site.

To investigate if this mechanism is influenced by the nature of the templating nucleobase, similar experiments were performed using DNA containing a thymine dimer or unmodified thymine. Time courses provided in Fig. 6C show similar trends in the fluorescence quenching and recovery phases using DNA containing thymine (green line), a thymine dimer (red line), or an abasic site (blue line). The time courses in each case show an initial decrease in fluorescence reflecting 5 NapIMP incorporation which is followed by a second, slower phase in fluorescence recovery. As before, the rate constants for 5 NapITP in corporation vary as a function of DNA lesion (vide supra). However, sig nificant differences are also observed in the fluorescence recovery phase with these different DNA substrates (Table 2). In particular, the 
A

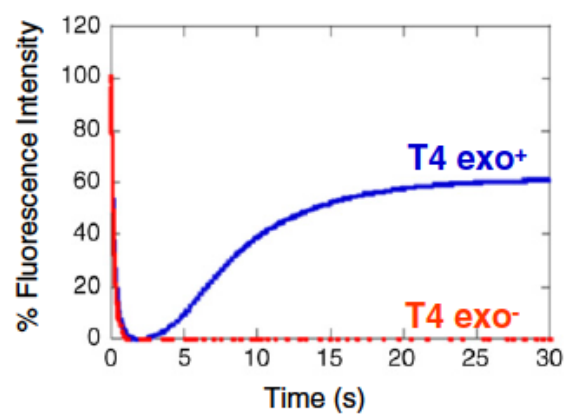

C

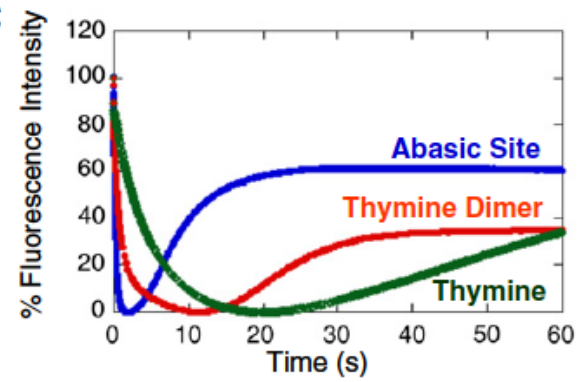

E

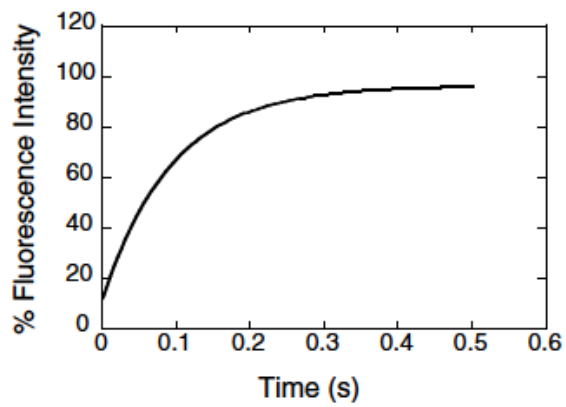

B

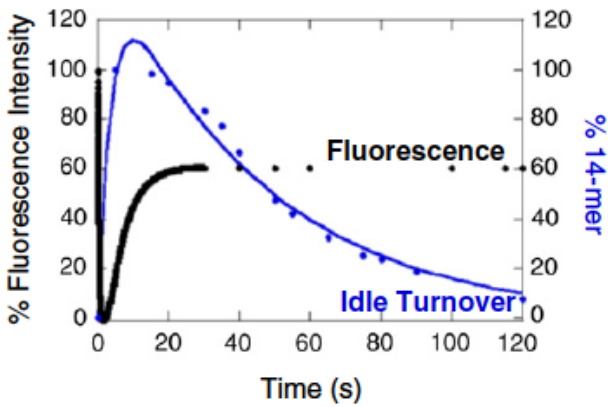

D

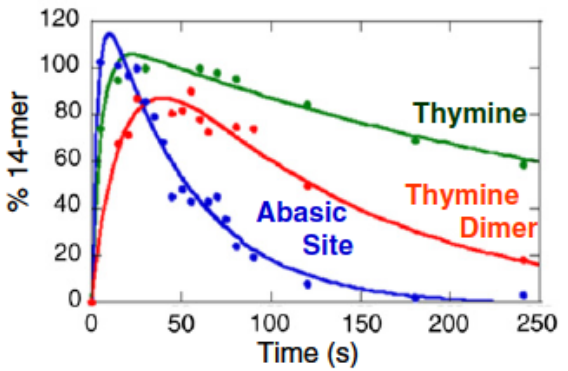

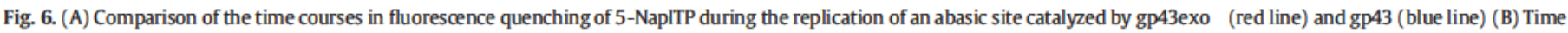

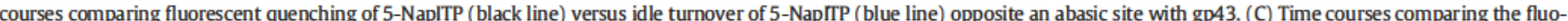

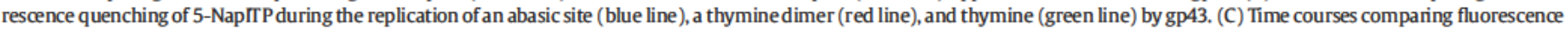

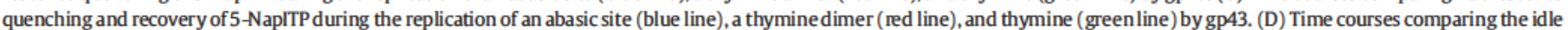

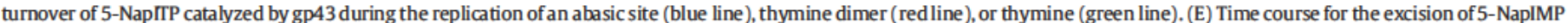
from single-stranded DNA by gp43.

$\mathrm{k}_{\text {recovery }}$ of $0.17 \pm 0.01 \mathrm{~s}^{-1}$ measured at an abasic site is 2 fold faster than the value of $0.08 \pm 0.01 \mathrm{~s}^{-1}$ measured at the thymine dimer and 4 fold faster than the value of $0.04 \pm 0.02 \mathrm{~s}^{-1}$ measured with thymine. The differences in fluorescence recovery suggest that the physical com position of the templating nucleobase influences the rate constant for "un stacking" of the non natural nucleotide.

Idle turnover measurements with these different DNA substrates were also performed to evaluate if the fluorescence recovery phase

Table 2

Summary of kinetic rate constants for 5-NapITP incorporation and excision opposite DNA lesions and undamaged DNA catalyzed by wild-type bacteriophage T4 DNA polymerase.

\begin{tabular}{lccc}
\hline DNA & $\mathrm{k}_{\text {quench }}\left(\mathrm{s}^{1}\right)^{\mathrm{a}}$ & $\mathrm{k}_{\text {recovery }}\left(\mathrm{s}^{1}\right)^{\mathrm{b}}$ & $\mathrm{k}_{\text {exo }}\left(\mathrm{s}^{1}\right)^{\mathrm{c}}$ \\
\hline $13 / 20_{\mathrm{SP}}$ & $5.6 \pm 0.1$ & $0.17 \pm 0.02$ & $0.024 \pm 0.004$ \\
$13 / 20_{\mathrm{T}} \mathrm{T}$ & $1.04 \pm 0.05$ & $0.08 \pm 0.02$ & $0.012 \pm 0.004$ \\
$13 / 20_{\mathrm{T}}$ & $0.22 \pm 0.03$ & $0.04 \pm 0.01$ & $0.0026 \pm 0.0003$ \\
\hline
\end{tabular}

${ }^{a} k_{\text {quench }}$ values are observed rate constants for the quenching in fluorescence of 5-NapITP as a function of DNA substrate.

b $\mathrm{k}_{\text {recovery }}$ values are observed rate constants for the recovery in fluorescence quenching of 5-NapITP.

${ }^{c} \mathbf{k}_{\text {exo }}$ values are observed rate constants for the enzymatic excision of 5-NapIMP from normal versus damaged DNA. is faster than the rate constant of hydrolytic excision. Time courses for in corporating and excising 5 NapIMP opposite an abasic site (blue line), a thymine dimer (red line), and thymine (green line) are provided in Fig. 6D. As illustrated, the hydrolytic excision of 5 NapIMP from DNA is fastest during the replication of an abasic site and significantly slower when replicating a thymine dimer or thymine. Kinetic simulation of the time courses was again used to calculate $\mathrm{k}_{\text {exo }}$ values. As summarized in Table 2 , the $k_{\text {exo }}$ values for all DNA substrates are significantly slower than the corresponding $\mathrm{k}_{\text {recovery }}$ values. For example, the $\mathrm{k}_{\text {exo }}$ value of $0.012 \pm 0.004 \mathrm{~s}^{-1}$ measured with a thymine dimer is $\sim 7$ fold slower than the $\mathrm{k}_{\text {recovery }}$ of $0.08 \pm 0.02 \mathrm{~s}^{-1}$. In addition, the rate constants for hydrolytic excision correlate with those measured in fluorescence recov ery as a function of DNA substrate. The $k_{\text {exo }}$ value of $0.012 \pm 0.004 \mathrm{~s}^{-1}$ measured with a thymine dimer is 2 fold slower that that measured from an abasic site $\left(k_{\text {exo }}=0.024 \pm 0.004 \mathrm{~s}^{-1}\right)$. In addition, the kexo value of $0.0026 \pm 0.0003 \mathrm{~s}^{-1}$ measured with thymine is $\sim 4.5$ fold slower that that measured from a thymine dimer.

We also quantified the ability of gp43 to degrade single stranded DNA containing 5 NapIMP (14Nap mer) at the terminal 3' position. This experiment was performed to determine the intrinsic rate constant for the enzymatic excision of the non natural nucleotide from DNA when not "paired" with a templating partner. Defining this rate con stant is important to evaluate if differences in aforementioned rate 
constants reflect interactions of 5 NapIMP paired with a templating partner rather than effects of the non natural nucleotide itself. Experi ments measuring the excision of 5 NapIMP from single stranded DNA were performed under single turnover by mixing $1 \mu \mathrm{M}$ gp43 with 250 nM 14Nap mer in the presence of $10 \mathrm{mM} \mathrm{Mg}^{2+}$. The time course pro vided in Fig. $6 \mathrm{E}$ shows an increase in fluorescence signal that reflects the generation of free 5 NapIMP caused by the hydrolysis of the non natural nucleotide from single stranded DNA. A rate constant of $10.6 \pm 0.2 \mathrm{~s}^{-1}$ is obtained from the fit of the data to the equation for a single exponential process (Eq. (2)). The $\mathrm{k}_{\text {exo }}$ value of $\sim 10 \mathrm{~s}^{-1}$ for excis ing 5 NapIMP with single stranded DNA is $>400$ times faster than the corresponding rate constants from opposite an abasic site or a thymine dimer. This large difference indicates that the slow $\mathrm{k}_{\text {exo }}$ values for excis ing 5 NapIMP from duplex DNA are not caused by an inability of the polymerase to efficiently process the non natural nucleobase. Instead, the measurable differences in rate constants with various duplex DNA substrates suggest that 5 NapIMP becomes "un stacked" via the forma tion of a pre exonuclease complex that occurs prior to enzymatic hy drolysis in the exonuclease active site. In addition, "un stacking" of the non natural nucleotide depends upon the physical composition of the templating nucleobase.

\section{Polymerase translocation competes with exonuclease proofreading}

Replicative fidelity is achieved, in part, by balancing the switch be tween polymerase and exonuclease active sites [44]. Our previous experiments evaluated the transition between active sites under condi tions that would not allow the formed mispair to be elongated. However, under physiological conditions, the presence of dNTPs could prevent partitioning of the mispair to the exonuclease domain and could allow the polymerase to extend the mispair. Indeed, increases in cellular levels of dNTPs via overexpression of ribonucleotide reductase in E. coli cause an increase in spontaneous mutagenesis [45]. In addition, a recent report by Fuchs and co workers indicates that increasing dNTP pools also plays an important role in induced mutagenesis in E. coli during the DNA damage response [46]. To test if similar effects could be observed with the bacteriophage T4 DNA polymerase, we used the spectroscopic properties of 5 NapITP to determine if adding the next correct nucleotide (dGTP) affects the formation of the pre excision complex during normal or translesion DNA synthesis. Representative data provided in Fig. 7A show that the addition of $150 \mu \mathrm{M}$ dGTP has a minimal effect on the initial fluorescence quenching phase or the subse quent recovery phase when using DNA containing an abasic site. Higher concentrations of dGTP $(>200 \mu \mathrm{M})$ reduced the amplitude of the initial fluorescence quenching phase without affecting the recovery phase (data not shown). The ability of dGTP to lower the amplitude of this initial phase indicates competition between dGTP and 5 NapITP for bind ing opposite the abasic site. However, the inability of dGTP to attenuate the fluorescence recovery phase suggests that the addition of the next correct nucleotide does not influence the transition between exonucle ase to polymerase active site during the replication of an abasic site.

Similar analyses were performed using undamaged DNA to deter mine if the presence of templating information influences translocation. Data provided in Fig. 7B show that increasing the concentration of the next correct nucleotide (100 $400 \mu \mathrm{M}$ ) causes an attenuation in the fluo rescence recovery phase with a minimal effect on the initial fluorescence quenching phase. The ability of the next correct nucleotide to hinder the "un stacking" of 5 NapIMP suggests that gp43 translocates to the next templating position when provided with the next correct nucleotide. Collectively, the difference in fluorescence recovery by the addition of the next correct dNTP as a function of DNA substrate suggests that gp43 not only senses damaged DNA differently from undamaged DNA but also appears to sense and respond differently to structurally diverse DNA lesions.

\section{Discussion}

The misreplication of damaged DNA is a leading cause of mutagene sis that is correlated with disease development [15 17] and drug resis tance [47 49]. While the link between mutagenesis and dysfunctional DNA replication is obvious, the molecular details describing how poly merases initiate and propagate mutagenic events still remain poorly de fined. One particular aspect lacking fundamental knowledge is with respect to the coordination of polymerization and exonuclease proof reading activities during normal and translesion DNA synthesis. In this report, we used the spectroscopic properties of the non natural nucleo tide, 5 NapITP, to evaluate how these activities function independently and collaboratively during normal and translesion DNA synthesis using gp43, the high fidelity bacteriophage T4 DNA polymerase, as a model. We chose this polymerase as a model for several reasons. First, gp43 is functionally homologous to eukaryotic DNA polymerases such as pol delta and pol epsilon that function during chromosomal DNA synthesis $[50,51]$. Secondly, the bacteriophage DNA polymerase possesses high sequence identity with other high fidelity DNA polymerases [52], and this sequence identity often correlates with structural identity in critical regions of the DNA polymerases associated with polymerization and exonuclease activities. Finally, we have previously demonstrated that gp43 uses 5 NapITP as a "universal" substrate when replicating unmodified DNA and structurally diverse DNA lesions [38,41]. In this re port, we validate that 5 NapITP is utilized as a novel fluorescent nucle otide analog to monitor the replication of damaged and unmodified DNA. Table 1 summarizes the rate constants for fluorescence quenching
A

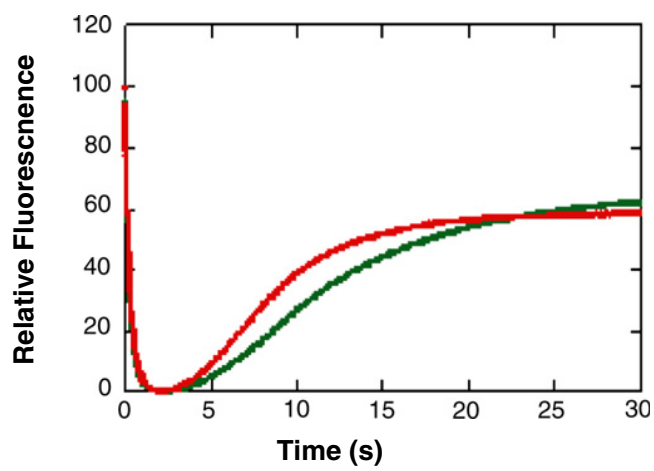

B

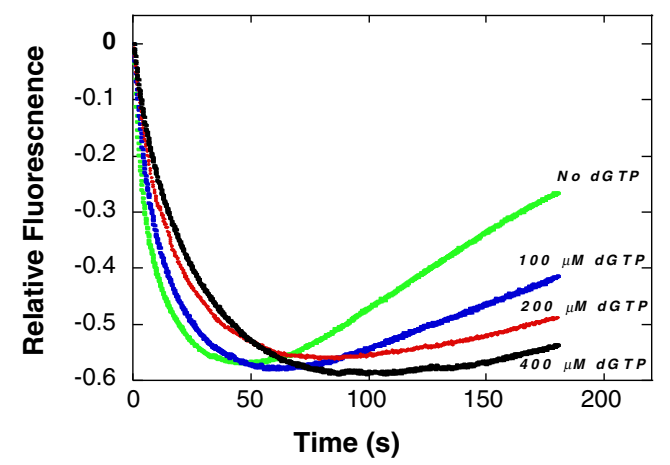

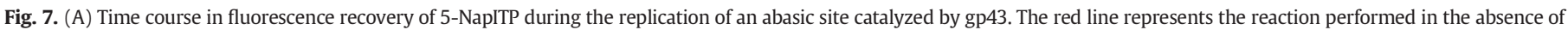

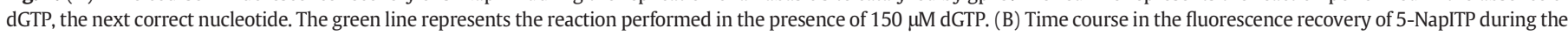

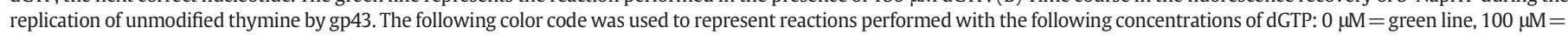
blue line, $200 \mu \mathrm{M}=$ red line, and $400 \mu \mathrm{M}=$ black line. 
and nucleotide incorporation of 5 NapIMP as a function of DNA tem plate. These results indicate that the high fidelity bacteriophage T4 DNA polymerase incorporates 5 NapIMP opposite normal and damaged DNA with different kinetic behaviors, and these differences suggest that distinct mechanisms are used during translesion and normal DNA synthesis. For example, rate constants for nucleotide incorporation and fluorescence quenching are highest with an abasic site and lowest during the replication of unmodified pyrimidines, thymine and cyto sine. During incorporation, there is a good correlation between the rate constants in fluorescence quenching with the proposed thermody namic stability of the formed mispair. In this case, the proposed thermo dynamic stability of the mispair is based upon the enhanced base stacking potential of the non natural nucleobase that is caused by its hydrophobic nature coupled with a large $\pi$ electron surface area $[32,37]$. As illustrated in Fig. 8, the faster rate constants for inserting 5 NapIMP opposite an abasic site likely reflect the maximized base stacking interactions of the non natural nucleotide paired oppo site the non instructional abasic site. In contrast, slower rate constants measured with unmodified pyrimidines suggest that steric hindrance imposed by either templating base impedes incorporation. Finally, rate constants obtained with the thymine dimer lie between those mea sured for the non instructional abasic site and templating pyrimidines. This result is consistent with previous reports indicating that a thymine dimer is replicated as a hybrid of a non instructional lesion and a templating base [41]. Collectively, the differences in rate constants as a function of DNA template indicate that 5 NapITP can be used as a mechanistic probe to differentiate between the replication of structural ly diverse DNA lesions.

Variations in the utilization of 5 NapITP also indicate the importance of several kinetic steps during the replication of distinct DNA lesions. For example, the conformational change step preceding phosphoryl transfer is the rate limiting step for incorporating 5 NapIMP opposite an abasic site. This is evident as the $\mathrm{k}_{\text {quench }}$ and $\mathrm{k}_{\text {inc }}$ values for inserting this non natural nucleotide are identical. Furthermore, the spectroscopic properties of 5 NapITP were used in a competition based assay to mea sure a $K_{i}$ value of $64+3 \mu \mathrm{M}$ for dATP opposite the non instructional abasic site. This $K_{i}$ value is essentially identical to the $K_{m}$ value of $80 \pm$ $10 \mu \mathrm{M}$ obtained via initial velocity studies using radioactive nucleotide incorporation assays [42]. The identity in $K_{m}$ and $K_{i}$ values indicates that binding of dATP to the Pol:DNA complex is in rapid equilibrium, and this argues that the conformational change preceding phosphoryl transfer is the rate limiting step for nucleotide incorporation opposite an abasic site. In addition, the biphasic time course monitoring the incor poration of 5 NapIMP opposite the lesion using pseudo first order reac tion conditions as well as the identity in time courses obtained using denaturing $(\mathrm{HCl})$ versus non denaturing (EDTA) quenching agents provides further evidence that this conformational change is the rate limiting step for nucleotide incorporation [41]. Finally, the identity in kinetic parameters measured using a fluorescence quenching assay versus a radiolabeled extension assay [31] is consistent with this mechanism. Collectively, these new kinetic data reinforce a model in which the conformational change preceding phosphoryl transfer is the rate limiting step for nucleotide insertion opposite an abasic site [42].

Similar approaches were used to demonstrate that the replication of a bulky thymine dimer is mechanistically different for that of an abasic site. With a thymine dimer, phosphoryl transfer appears to be partially rate limiting since the rate constant in fluorescence quenching of 5 NapITP is faster than the rate constant for incorpora tion. This was subsequently confirmed by a sub stoichiometric burst in product formation as well as in the differences in product forma tion detected using denaturing versus non denaturing quenching agents. Finally, the fluorescent competition based assay was also used to measure a $K_{i}$ value of $125 \mu \mathrm{M}$ for dATP opposite the thymine dimer. The $K_{i}$ value is 2 fold higher than that measured for the
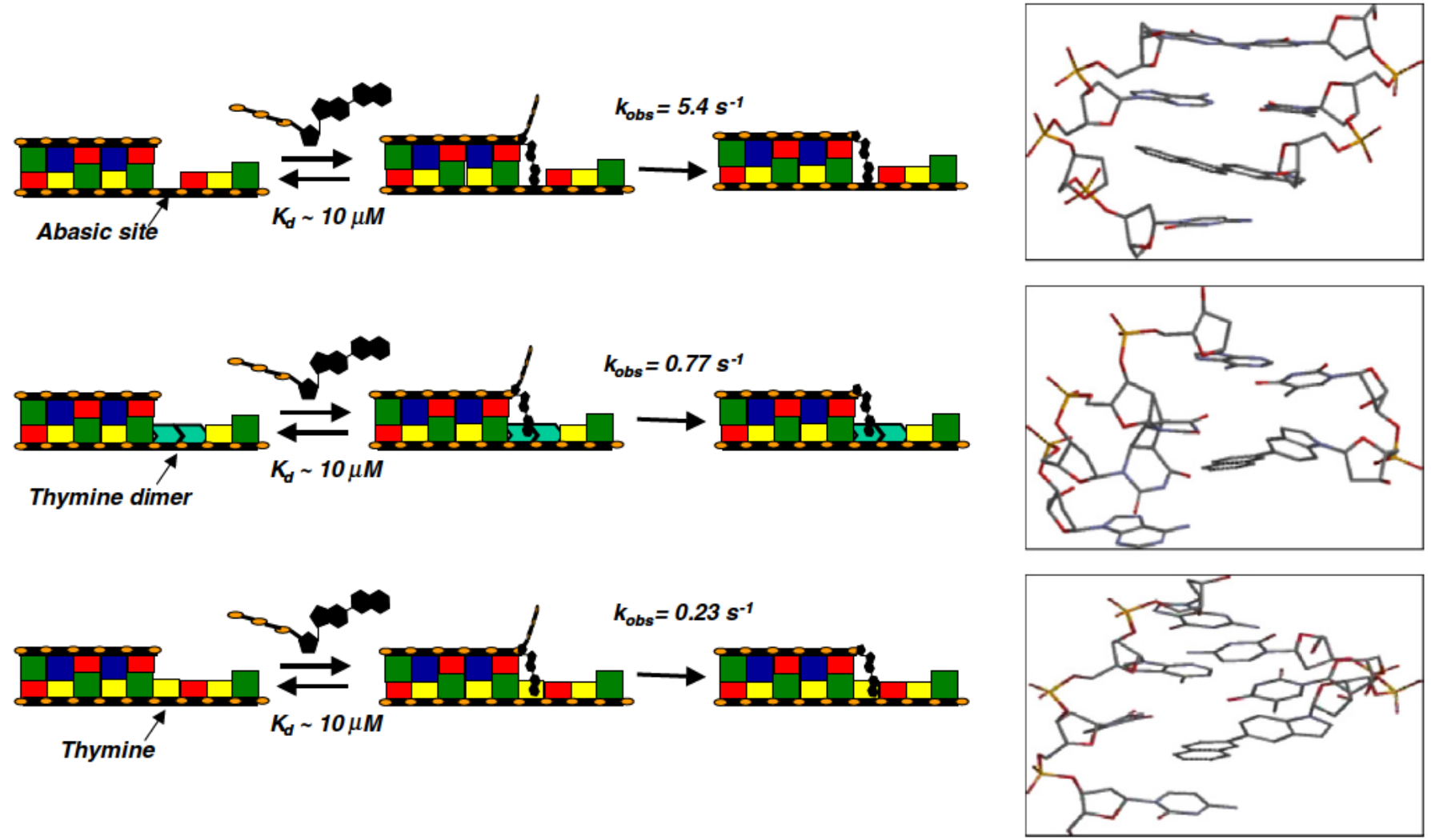

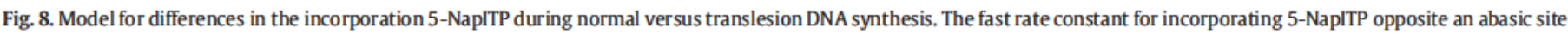

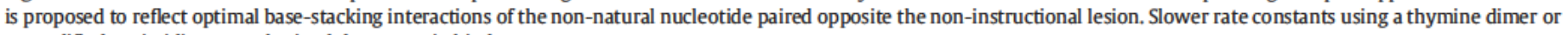
unmodified pyrimidines are obtained due to steric hindrance. 
non instructional abasic site. This difference in binding affinity is sur prising since a thymine dimer contains potential coding information while the abasic site lacks direct coding information. It is possible that crosslinking two adjacent thymines causes significant distortion in the DNA template and disrupts nucleotide binding more signifi cantly than the complete lack of templating information at an abasic site. Indeed, it is well known that alterations to a templating base in DNA can adversely affect the mechanism of DNA synthesis. This is borne out from the numerous structures of different DNA polymer ases bound to various forms of DNA damage including abasic sites [53 56] and thymine dimers [19,57]. Each structure illustrates how perturbations in DNA sequence affect the conformation of templating DNA and/or polymerase to alter the efficiency and fidelity of nucleo tide incorporation. However, these structures only provide snapshots of thermodynamically favored species. Our studies using 5 NapITP have the advantage of measuring the kinetic pathways associated with nucleotide selection, incorporation, and excision as a function of DNA lesion. In fact, the data provided here collectively show that kinetic behavior of the high fidelity bacteriophage T4 DNA polymer ase is differentially influenced by the physical nature of DNA lesion. The next logical step is to combine structural analyses of DNA poly merases with this spectroscopic probe to fully define differences be tween normal and translesion DNA synthesis.

The spectroscopic properties of 5 NapITP also confirmed the pres ence of a pre excision complex that forms prior to hydrolysis of the mispaired primer. This is evident as the rate constant in fluorescence quenching is significantly faster than the rate constant for excising 5 NapIMP (Table 2). These rate constants in fluorescence recovery and excision vary as a function of templating base and again reiterate that processing of a mispaired primer template is dependent upon its physical nature. In particular, faster rate constants are measured when 5 NapIMP is paired opposite an abasic site compared to either thymine dimer or unmodified thymine. This trend is somewhat surprising since we predicted that 5 NapIMP would be excised much slower when paired opposite an abasic site due to better base stacking interactions of the non natural nucleotide with the non instructional DNA lesion. This prediction is based on the fact that there is usually an inverse correlation between the rates of dNMP excision ( $\left.k_{\text {exo }}\right)$ with the rates of dNTP incorporation $\left(k_{\text {pol }}\right)$. In general, polymerases are more proficient at excising a mispair that is kinetically more challenging to form. Indeed, we demonstrated that this correlation exists during the insertion and excision of dAMP opposite an abasic site as the rate constant for excising dAMP from the lesion $\left(k_{\text {exo }} \sim 28 \mathrm{~s}^{-1}\right.$ ) is much faster than incorporating dAMP opposite an abasic site $\left(k_{\text {pol }} \sim 0.15 \mathrm{~s}^{-1}\right)$ [34]. However, this mechanism does not appear to function when non natural nucleotides are placed in the primer as the results provided in Table 2 indicate that the 5 naphthylindole:thymine and 5 naphthylindole:thymine dimer mispairs are actually degraded more slowly despite being predicted to be less thermodynamically stable than 5 napthylindole:abasic site. This paradox can be explained if exonuclease proofreading is activated through an inability to translocate to the next templating position rath er than through simply sensing the nucleobase in the primer strand. This argument is based on data demonstrating that gp43 rapidly excises 5 NapIMP as it is unable to translocate to the next templating base when supplied with the next correct nucleotide. Likewise, the slower rate constants for excising 5 NapIMP from opposite a templating thy mine could be caused by the ability of gp 43 to translocate rather than partition the non natural nucleotide into the exonuclease active site.

This last aspect is of particular importance toward understanding the cellular mechanisms of lesion bypass. Under cellular conditions, most replicative DNA polymerases are complexed with accessory proteins that enhance the overall processivity of the DNA replication process [58]. When replicating undamaged DNA, the interaction of the circular "clamp" protein with the DNA polymerase decreases the rate constant of polymerase dissociation from DNA to greatly increase its low intrinsic processivity [59]. In addition, these circular clamp proteins act as a cellu lar scaffold to recruit specialized DNA polymerase that can efficiently replicate various DNA lesions that typically serve as strong replication blocks to high fidelity DNA polymerases [60]. Our results showing that exonuclease proofreading is activated by the inability of a DNA polymer ase to translocate beyond a DNA lesion have important ramifications for this potential cellular mechanism. For example, the interactions of a rep licative DNA polymerase with its processivity factor would hinder disso ciation from the DNA lesion and essentially force the polymerase to remain bound and stalled at the site of DNA damage. Stalling of the rep licative polymerase directly at the lesion would preclude access to spe cialized DNA polymerases that could maintain the continuity of cellular DNA synthesis by efficiently inserting and/or extending beyond the lesion. However, the activation of exonuclease activity would allow the replicative polymerase to move back several bases downstream and allow a specialized DNA polymerase access to the DNA lesion. While this is a hypothetical model, we envision that non natural nucle otides such as 5 NapITP can be used as chemical tools to further define the mechanism and dynamics of intramolecular movements between polymerization and exonuclease active sites and how this influences the coordination of polymerase switching during lesion by pass. Since the bacteriophage T4 system is limited to a single DNA polymerase, the prokaryotic $E$. coli system provides the next simplest system to eval uate this mechanism.

\section{References}

[1] L.K. Clayton, M.F. Goodman, E.W. Branscomb, D.J. Galas, Error induction and correction by mutant and wild type T4 DNA polymerases. Kinetic error discrimination mechanisms, J. Biol. Chem. 254 (1979) 1902-1912.

[2] M.E. Santos, J.W. Drake, Rates of spontaneous mutation in bacteriophage T4 are independent of host fidelity determinants, Genetics 138 (1994) 553-564

[3] T.A. Kunkel, R.D. Sabatino, R.A. Bambara, Exonucleolytic proofreading by calf thymus DNA polymerase delta, Proc. Natl. Acad. Sci. U. S. A. 84 (1987) 4865-4869.

[4] L.A. Loeb, M.E. Reyland, Fidelity of DNA synthesis, in: F. Eckstein, D.M.J. Lilley (Eds.), Nucleic Acids and Molecular Biology, Springer-Verlag, Berlin, 1987, pp. 157-173.

[5] B.D. Preston, B.J. Poiesz, L.A. Loeb, Fidelity of HIV-1 reverse transcriptase, Science 242 (1988) 1168-1171.

[6] T.A. Kunkel, The mutational specificity of DNA polymerase-beta during in vitro DNA synthesis. Production of frameshift, base substitution, and deletion mutations, J. Biol. Chem. 260 (1985) 5787-5796.

[7] T.A. Kunkel, K. Bebenek, DNA replication fidelity, Annu. Rev. Biochem. 69 (2000) 497-529.

[8] M.F. Goodman, S. Creighton, L.B. Bloom, J. Petruska, Biochemical basis of DNA replication fidelity, Crit. Rev. Biochem. Mol. Biol. 28 (1993) 83-126.

[9] S. Creighton, M.F. Goodman, Gel kinetic analysis of DNA polymerase fidelity in the presence of proofreading using bacteriophage T4 DNA polymerase, J. Biol. Chem. 270 (1995) 4759-4774.

[10] T.L. Capson, J.A. Peliska, B.F. Kaboord, M.W. Frey, C. Lively, M. Dahlberg, S.J Benkovic, Kinetic characterization of the polymerase and exonuclease activities of the gene 43 protein of bacteriophage T4, Biochemistry 31 (1992) 10984-10994.

[11] H. Cai, H. Yu, K. McEntee, T.A. Kunkel, M.F. Goodman, Purification and properties of wild-type and exonuclease-deficient DNA polymerase II from Escherichia coli, J. Biol. Chem. 270 (1995) 15327-15335.

[12] H. Huang, P. Keohavong, Fidelity and predominant mutations produced by deep vent wild-type and exonuclease-deficient DNA polymerases during in vitro DNA amplification, DNA Cell Biol. 15 (1996) 589-594.

[13] M.J. Longley, D. Nguyen, T.A. Kunkel, W.C. Copeland, The fidelity of human DNA polymerase gamma with and without exonucleolytic proofreading and the p55 accessory subunit, J. Biol. Chem. 276 (2001) 38555-38562.

[14] M. de Vega, L. Blanco, M. Salas, Processive proofreading and the spatial relationship between polymerase and exonuclease active sites of bacteriophage phi29 DNA polymerase, J. Mol. Biol. 292 (1999) 39-51.

[15] L.A. Loeb, Cancer cells exhibit a mutator phenotype, Adv. Cancer Res. 72 (1998) 25-56.

[16] E. Crespan, A. Amoroso, G. Maga, DNA polymerases and mutagenesis in human cancers, Subcell. Biochem. 50 (2010) 165-188.

[17] R. Yoshida, K. Miyashita, M. Inoue, A. Shimamoto, Z. Yan, A. Egashira, E. Oki, Y. Kakeji, S. Oda, Y. Maehara, Concurrent genetic alterations in DNA polymerase proofreading and mismatch repair in human colorectal cancer, Eur. J. Hum. Genet. 19 (2011) 320-325.

[18] G.W. Hsu, M. Ober, T. Carell, L.S. Beese, Error-prone replication of oxidatively damaged DNA by a high-fidelity DNA polymerase, Nature 431 (2004) 217-221.

[19] Y. Li, S. Dutta, S. Doublié, H.M. Bdour, J.S. Taylor, T. Ellenberger, Nucleotide insertion opposite a cis-syn thymine dimer by a replicative DNA polymerase from bacteriophage T7, Nat. Struct. Mol. Biol. 11 (2004) 784-790. 
[20] B. Devadoss, I. Lee, A.J. Berdis, Enhancing the "A-rule" of translesion DNA synthesis: promutagenic DNA synthesis using modified nucleoside triphosphates, Biochemistry 46 (2007) 13752-13761.

[21] J.N. Patro, M. Urban, R.D. Kuchta, Interaction of human DNA polymerase alpha and DNA polymerase I from Bacillus stearothermophilus with hypoxanthine and 8-oxoguanine nucleotides, Biochemistry 48 (2009) 8271-8278.

[22] M.S. Noé, A.C. Ríos, Y. Tor, Design, synthesis, and spectroscopic properties of extended and fused pyrrolo-dC and pyrrolo-C analogs, Org. Lett. 14 (2012) 3150-3153.

[23] Y. Saito, K. Hanawa, K. Hayashi, K. Motegi, A. Okaoto, I. Saito, Synthesis and properties of novel base-discriminating fluorescent (BDF) nucleosides, Nucleic Acids Symp. Ser. (Oxf) 49 (2005) 153-154.

[24] S.S. Bag, Y. Saito, K. Hanawa, S. Kodate, I. Suzuka, I. Saito, Intelligent fluorescent nucleoside in sensing cytosine base: importance of hydrophobic nature of perylene fluorophore, Bioorg. Med. Chem. Lett. 16 (2006) 6338-6341.

[25] A.K. Shchyolkina, D.N. Kaluzhny, O.F. Borisova, M.E. Hawkins, R.L. Jernigan, T.M. Jovin, D.J. Arndt-Jovin, V.B. Zhurkin, Formation of an intramolecular triplestranded DNA structure monitored by fluorescence of 2-aminopurine or 6-methylisoxanthopterin, Nucleic Acids Res. 32 (2004) 432-440.

[26] M. Narayanan, G. Kodali, V. Singh, Y. Xing, M.E. Hawkins, R.J. Stanley, Differential fluorescence quenching of fluorescent nucleic acid base analogues by native nucleic acid monophosphates, J. Phys. Chem. B 114 (2010) 5953-5963.

[27] S. Preus, K. Kilså, L.M. Wilhelmsson, B. Albinsson, Photophysical and structural properties of the fluorescent nucleobase analogues of the tricyclic cytosine (tC) family, Phys. Chem. Chem. Phys. 12 (2010) 8881-8892.

[28] M.W. Frey, L.C. Sowers, D.P. Millar, S.J. Benkovic, The nucleotide analog 2-aminopurine as a spectroscopic probe of nucleotide incorporation by the Klenow fragment of Escherichia coli polymerase I and bacteriophage T4 DNA polymerase, Biochemistry 34 (1995) 9185-9192.

[29] E. Fidalgo da Silva, S.S. Mandal, L.J. Reha-Krantz, Using 2-aminopurine fluorescence to measure incorporation of incorrect nucleotides by wild type and mutant bacteriophage T4 DNA polymerases, J. Biol. Chem. 277 (2002) 40640-40649.

[30] D.N. Mhaskar, M.F. Goodman, On the molecular basis of transition mutations. Frequency of forming 2-aminopurine-cytosine base mispairs in the G X C-A X T mutational pathway by T4 DNA polymerase in vitro, J. Biol. Chem. 259 (1984) 11713-11717.

[31] X. Zhang, A. Donnelly, I. Lee, A.J. Berdis, Rational attempts to optimize non-natura nucleotides for selective incorporation opposite an abasic site, Biochemistry 45 (2006) 13293-13303.

[32] X. Zhang, I. Lee, A.J. Berdis, The use of nonnatural nucleotides to probe the contributions of shape complementarity and pi-electron surface area during DNA polymerization, Biochemistry 44 (2005) 13101-13110.

[33] J. Rush, W.H. Konigsberg, Rapid purification of overexpressed T4 DNA polymerase, Prep. Biochem. 19 (1989) 329-340.

[34] X. Zhang, I. Lee, A.J. Berdis, A potential chemotherapeutic strategy for the selective inhibition of promutagenic DNA synthesis by nonnatural nucleotides, Biochemistry 44 (2005) 13111-13121.

[35] E.Z. Reineks, A.J. Berdis, Evaluating the contribution of base stacking during translesion DNA replication, Biochemistry 43 (2004) 393-404.

[36] X. Zhang, I. Lee, A.J. Berdis, Evaluating the contributions of desolvation and base-stacking during translesion DNA synthesis, Org. Biomol. Chem. 2 (2004) 1703-1711.

[37] X. Zhang, I. Lee, X. Zhou, A.J. Berdis, Hydrophobicity, shape, and pi-electron contributions during translesion DNA synthesis, J. Am. Chem. Soc. 128 (2006) 143-149.

[38] D. Vineyard, X. Zhang, A. Donnelly, I. Lee, A.J. Berdis, Optimization of non-natural nucleotides for selective incorporation opposite damaged DNA, Org. Biomol. Chem. 5 (2007) 3623-3630.
[39] I. Lee, A. Berdis, Fluorescent analysis of translesion DNA synthesis by using a novel, nonnatural nucleotide analogue, Chembiochem 7 (2006) 1990-1997.

[40] S.P. Gilbert, A.T. Mackey, Kinetics: a tool to study molecular motors, Methods 22 (2000) 337-354.

[41] B. Devadoss, I. Lee, A.J. Berdis, Is a thymine dimer replicated via a transient abasic site intermediate? A comparative study using non-natural nucleotides, Biochemistry 46 (2007) 4486-4498.

[42] A.J. Berdis, Dynamics of translesion DNA synthesis catalyzed by the bacteriophage T4 exonuclease-deficient DNA polymerase, Biochemistry 40 (2001) 7180-7191.

[43] H.E. Gray, W.G. Luttge, Linearization of two ligand-one binding site scatchard plot and the "IC50" competitive inhibition plot: application to the simplified graphical determination of equilibrium constants, Life Sci. 42 (1988) 231-237.

[44] E. Fidalgo da Silva, L.J. Reha-Krantz, DNA polymerase proofreading: active site switching catalyzed by the bacteriophage T4 DNA polymerase, Nucleic Acids Res. 35 (2007) 5452-5463.

[45] L.J. Wheeler, I. Rajagopal, C.K. Mathews, Stimulation of mutagenesis by proportional deoxyribonucleoside triphosphate accumulation in Escherichia coli, DNA Repair (Amst) 4 (2005) 1450-1456.

[46] S. Gon, R. Napolitano, W. Rocha, S. Coulon, R.P. Fuchs, Increase in dNTP pool size during the DNA damage response plays a key role in spontaneous and induced-mutagenesis in Escherichia coli, Proc. Natl. Acad. Sci. U. S. A. 108 (2011) 19311-19316.

[47] J.G.G. Lerma, W. Heneine, Resistance of human immunodeficiency virus type 1 to reverse transcriptase and protease inhibitors: genotypic and phenotypic testing, J. Clin. Virol. 21 (2001) 197-212.

[48] R.S. Galhardo, R. Do, M. Yamada, E.C. Friedberg, P.J. Hastings, T. Nohmi, S.M. Rosenberg, DinB upregulation is the sole role of the SOS response in stressinduced mutagenesis in Escherichia coli, Genetics 182 (2009) 55-68.

[49] A.J. Moyano, A.M. Smania, Simple sequence repeats and mucoid conversion: biased mucA mutagenesis in mismatch repair-deficient Pseudomonas aeruginosa, PLoS One 4 (2009) e8203.

[50] T.A. Kunkel, P.M. Burgers, Dividing the workload at a eukaryotic replication fork, Trends Cell Biol. 18 (2008) 521-527.

[51] U. Hubscher, G. Maga, S. Spadari, Eukaryotic DNA polymerases, Annu. Rev. Biochem. 71 (2002) 133-163.

[52] D.K. Braithwaite, J. Ito, Compilation, alignment, and phylogenetic relationships of DNA polymerases, Nucleic Acids Res. 21 (1993) 787-802.

[53] E. Freisinger, A.P. Grollman, H. Miller, C. Kisker, Lesion (in)tolerance reveals insights into DNA replication fidelity, EMBO J. 23 (2004) 1494-1505.

[54] M. Hogg, S.S. Wallace, S. Doublié, Crystallographic snapshots of a replicative DNA polymerase encountering an abasic site, EMBO J. 23 (2004) 1483-1493.

[55] K.E. Zahn, H. Belrhali, S.S. Wallace, S. Doublié, Caught bending the A-rule: crystal structures of translesion DNA synthesis with a non-natural nucleotide, Biochemistry 46 (2007) 10551-10561.

[56] S. Obeid, N. Blatter, R. Kranaster, A. Schnur, K. Diederichs, W. Welte, A. Marx, Replication through an abasic DNA lesion: structural basis for adenine selectivity, EMBO J. 29 (2010) 1738-1747.

[57] H. Ling, F. Boudsocq, B.S. Plosky, R. Woodgate, W. Yang, Replication of a cis-syn thymine dimer at atomic resolution, Nature 424 (2003) 1083-1087.

[58] M.A. Trakselis, M.U. Mayer, F.T. Ishmael, R.M. Roccasecca, S.J. Benkovic, Dynamic proteins interactions in the bacteriophage T4 replisome, Trends Biochem. Sci. 26 (2001) 566-572.

[59] Z. Kelman, J. Hurwitz, M. O'Donnell, Processivity of DNA polymerases: two mechanisms, one goal, Structure 6 (1998) 121-125.

[60] A.R. Lehmann, Clubbing together on clamps: the key to translesion synthesis, DNA Repair (Amst) 5 (2006) 404-407. 